\title{
Impact of High-temperature Forced-air Heating of Navel Oranges on Quality Attributes, Sensory Parameters, and Flavor Volatiles
}

\author{
David Obenland ${ }^{1}$ \\ San Joaquin Valley Agricultural Sciences Center, USDA-ARS, 9611 S. Riverbend \\ Avenue, Parlier, CA 93648
}

\author{
Sue Collin, James Sievert, and Mary Lu Arpaia \\ Department of Botany and Plant Sciences, University of California, Riverside, \\ CA 92521
}

Additional index words. waxing, quarantine, soluble solids, acidity, esters

\begin{abstract}
Navel oranges were subjected to high-temperature forced-air (HTFA) treatment to evaluate the effect on quality and sensory attributes as well as flavor volatiles of a treatment protocol designed to disinfest citrus of Anastrepha spp. fruit flies. The treatment consisted of heating the fruit to a core temperature of $44^{\circ} \mathrm{C}$ and then holding it there for $100 \mathrm{~min}$, after which the fruit were placed into storage for 4 weeks. The fruit were removed from storage and evaluated for surface injury, soluble solids concentration (SSC), titratable acidity (TA), and then judged for sensory characteristics by a semiexpert panel. In a separate experiment, fruit were removed at 30 -min intervals from the treatment chamber and sensory quality as well as flavor volatiles determined to obtain an estimate of when the flavor changes occurred. It was found that the HTFA treatment caused a significant loss in flavor quality that was most closely linked to a loss in the fresh flavor of the fruit. The HTFA-treated fruit were also determined by panelists to be less sweet, although the SSC/TA ratio was increased by treatment. Neither storage nor waxing after treatment appeared to alter the HTFA effect, although waxing before treatment greatly enhanced the negative effect on flavor. Flavor began to be significantly affected during the final $\mathbf{3 0} \mathrm{min}$ of treatment. The flavor changes occurred at the same time as large increases in the amount of four esters, two of which were present in concentrations exceeding aroma thresholds and are likely involved in the loss in flavor quality induced by HTFA treatment.
\end{abstract}

Quarantine treatment of citrus for insect disinfestation is sometimes needed to be able to export fruit to various trading partners throughout the world. Although chemical fumigation has been often used for this purpose, legislative pressure and consumer desire for organic products are prompting a search for non-chemical alternatives. Treatment with high temperatures is an effective means of disinfestation that can be achieved in a timeframe similar to that of fumigation. Treatment with HTFA is generally thought to be the gentlest means of heat treatment with regard to its effect on fruit quality (McGuire, 1991). Favorable results were reported regarding the effect of HTFA on citrus quality (McGuire, 1991; Miller and McDonald, 1997; Sharp and McGuire, 1996), which gave optimism that this could be a relatively easy and effective alternative to chemical fumigation. Based on these and other results, a method for HTFA treatment (T103-b-1) was published in the USDA APHIS treatment manual

Received for publication 16 Dec. 2011. Accepted for publication 13 Jan. 2012.

${ }^{1}$ To whom reprint requests should be addressed; e-mail david.obenland@ars.usda.gov. corresponded to the flavor loss that was observed.

More recently, a newer protocol (T103-a-1) has been published in the USDA APHIS treatment manual for the disinfestation of Anastrepha spp. in citrus (APHIS, 2012) that uses a final core temperature of $44{ }^{\circ} \mathrm{C}$ rather than the higher temperature of $47.2^{\circ} \mathrm{C}$ that was used in our previous work (Obenland et al., 1999). The objectives of this study were to: 1) evaluate the impact of this newer, potentially less injurious protocol on navel orange sensory quality; 2) examine more closely the impact of fruit waxing on sensory quality as influenced by HTFA treatment; and 3) examine the effect of HTFA treatment on flavor volatiles to better understand the impact of this treatment on flavor.

\section{Materials and Methods}

Fruit

Navel oranges (Citrus sinensis L. Osbeck 'Washington') were harvested from research plots at the University of California Lindcove Research and Extension Center near Exeter, CA. Care was taken to harvest fruit that were size 56 (56 fruit in a $18.14-\mathrm{kg}$ carton). Harvests occurred the day before the initial treatment and the fruit was then transported to the San Joaquin Valley Agricultural Sciences Center in Parlier, CA, where the fruit were equilibrated overnight at a temperature of $23{ }^{\circ} \mathrm{C}$. Fruit for all tests were harvested in the middle of February, corresponding to midseason in California. For replications of experiments that occurred on subsequent days, the fruit were held at $5^{\circ} \mathrm{C}$ and warmed up again as needed.

High-temperature forced-air treatment

HTFA was applied using the APHIS T103-b-1 treatment protocol for the disinfestation of Anastrepha spp. from citrus (APHIS, 2012). According to the protocol, fruit are heated until the core temperature reaches $44{ }^{\circ} \mathrm{C}$, after which the core temperature is held for a period of $100 \mathrm{~min}$. The core must take at least 90 min to reach $44^{\circ} \mathrm{C}$. Heat was applied in our study by use of a forced-air treatment chamber designed by Techni-Systems (Chelan, WA) that was able to precisely control air temperature, dew point, and air speed. This unit was as previously described (Obenland et al., 2005) with the exception that the oxygen and carbon dioxide composition within the chamber was not controlled during the treatment runs. Temperature probes were used to monitor fruit surface and core temperatures during the run. Dew point was maintained at $2{ }^{\circ} \mathrm{C}$ below the temperature of the coolest probed fruit. The chamber temperature was set at a constant $45^{\circ} \mathrm{C}$ until the core reached $44{ }^{\circ} \mathrm{C}$, when the temperature was lowered to $44.5{ }^{\circ} \mathrm{C}$. Fruit core temperatures typically required from 120 to $140 \mathrm{~min}$ to reach $44^{\circ} \mathrm{C}$. Air speed was maintained at $2 \mathrm{~m} \cdot \mathrm{s}^{-1}$ throughout the run.

Test 1: Influence of high-temperature forced air and waxing on sensory and quality attributes. Four different treatments were 
conducted with a total of 720 randomized navel oranges for this test: 1) HTFA, unwaxed; 2) HTFA, waxed; 3 ) control, unwaxed; and 4) control waxed. Fruit (120) were equilibrated at $23{ }^{\circ} \mathrm{C}$ overnight and then were treated in each of three replicate HTFA runs with half of the HTFA-treated fruit being waxed using Britex 505 (Brogdex Co., Pomona, CA) with $2000 \mu \mathrm{L} \cdot \mathrm{L}^{-1}$ imazalil (Fungaflor 500EC; Pace International, Seattle, WA) after the fruit had been allowed to cool at ambient $\left(\cong 23{ }^{\circ} \mathrm{C}\right)$ temperature for a period of $1 \mathrm{~h}$. The same number of control fruit (120) were kept at $23{ }^{\circ} \mathrm{C}$ for the duration of the treatment run and half of these waxed at the same time as the HTFA-treated fruit. Wax for both HTFAtreated and untreated fruit was applied by hand followed by drying on a wire rack at $23{ }^{\circ} \mathrm{C}$ with turning of the fruit and hand-wiping performed as needed to eliminate drips that formed. After treatment and waxing (if applied), half of the fruit from each replication was kept at $23{ }^{\circ} \mathrm{C}$ for $24 \mathrm{~h}$ and then evaluated, whereas the other half were kept in storage for 3 weeks at $5^{\circ} \mathrm{C}$ followed by $4 \mathrm{~d}$ at $20^{\circ} \mathrm{C}$ and then $3 \mathrm{~d}$ at $13{ }^{\circ} \mathrm{C}$ to simulate storage, shipping, and marketing before evaluation. The evaluations that were conducted included both sensory and quality attributes and are described in separate sections. A total of 30 fruit was used for each treatment/storage combination. Three replicates were performed for each treatment with the waxed and unwaxed fruit being treated together in three separate HTFA runs, all being completed in a single day.

Test 2: Effect of waxing timing. The purpose of this test was to ascertain if it made any difference to sensory quality when the wax is applied in relation to the HTFA treatment. Thirty fruit were randomly assigned to each treatment with three replicates, every replicate for the HTFA-treated fruit being a separate HTFA run containing each of the three treatments. HTFA-treated fruit were: 1) never waxed; 2) waxed before treatment; or 3) waxed after treatment. The applied wax was the same as detailed in Test 1 and was applied after the fruit had cooled for $1 \mathrm{~h}$ at ambient temperature if it was applied after HTFA treatment. Control fruit remained at ambient temperature throughout the HTFA treatment and were waxed with the same timing options as the HTFA-treated fruit. Evaluations of all fruit for sensory quality were conducted after 3 weeks of storage at $5^{\circ} \mathrm{C}$ followed by $4 \mathrm{~d}$ at $20^{\circ} \mathrm{C}$ and then $3 \mathrm{~d}$ at $13{ }^{\circ} \mathrm{C}$ to simulate storage, shipping, and marketing.

Test 3: Influence of treatment duration on sensory attributes and flavor volatiles. To determine the timing of when navel orange flavor first becomes affected as a result of HTFA treatment and assay flavor volatile composition at each time point, fruit were randomly removed from the treatment chamber every $30 \mathrm{~min}$ during the duration of the HTFA treatment. As a result of the use of a special airlock system that attached to the front of the chamber, it was possible to do this with only minimal disruption to the temperature profile. A total of 25 fruit was removed at each time point with there being a total of nine time points when Time 0 is included. This treatment was replicated three times, each treatment being an individual HTFA run. After HTFA treatment, the fruit were allowed to stand at ambient temperature for 1 $\mathrm{h}$ after which they were hand-waxed using undiluted Fruit-A-Peel C (Fruit Growers Supply, Lindsay, CA) and placed into storage at $5{ }^{\circ} \mathrm{C}$ for 3 weeks followed by storage at $20{ }^{\circ} \mathrm{C}$ for 1 week.

\section{Quality and sensory evaluation}

Oranges were evaluated for sensory quality with a portion of each fruit being juiced, the juice being immediately frozen at $-20{ }^{\circ} \mathrm{C}$ and saved for assay of the flavor volatile composition. Fifteen fruit per time point were evaluated for sensory characteristics and

samples from eight of these fruit were measured for flavor volatile composition. Initial preparation consisted of taking the oranges from storage, washing and drying them, and allowing the fruit to adjust to ambient temperature. For Test 1, the fruit were first evaluated for marketability with fruit that had no or slight surface damage being considered as marketable. Surface damage generally occurred in the form of rind pitting and was considered to be slight if the pits were small (less than $2 \mathrm{~mm}$ ) and found on $20 \%$ of the fruit surface or less. After evaluation for marketability (if performed), the top and bottom third of each fruit was cut away and discarded, leaving a $2.5-\mathrm{cm}$ section of the center portion of the fruit for testing. Each fruit section was then cut in half crosswise and one half used for

Table 1. Effect of quarantine high-temperature forced-air treatment, waxing, and storage $\mathrm{z}^{\mathrm{z}}$ for either $1 \mathrm{~d}$ or 4 weeks on navel orange fruit quality and sensory attributes. ${ }^{\mathrm{y}}$

\begin{tabular}{lcccccccc}
\hline Treatment & $\begin{array}{c}\text { Percent } \\
\text { marketable }^{\mathrm{x}}\end{array}$ & $\begin{array}{c}\text { SSC } \\
\left.{ }^{\circ} \text { Brix }\right)\end{array}$ & TA $(\%)$ & SSC/TA & Hedonic & & & \\
Sweetness $^{\mathrm{v}}$ & Tartness $^{\mathrm{v}}$ & Freshness $^{\mathrm{v}}$ \\
\hline No heat & 93.0 & 13.8 & 0.69 & 20.4 & 5.9 & 113.6 & 111.6 & 87.8 \\
HTFA & 94.0 & 13.6 & 0.57 & 24.4 & 4.6 & 105.7 & 117.9 & 56.3 \\
No wax & 94.2 & 13.6 & 0.63 & 22.4 & 5.5 & 110.7 & 115.6 & 77.1 \\
Waxed & 92.8 & 13.8 & 0.63 & 22.4 & 5.0 & 108.7 & 113.9 & 67.0 \\
1-d storage & 95.5 & 13.9 & 0.68 & 20.8 & 6.1 & 118.7 & 114.4 & 88.8 \\
4 weeks storage & 91.5 & 13.6 & 0.58 & 24.0 & 4.4 & 100.7 & 115.1 & 55.3
\end{tabular}

\begin{tabular}{lcccccccc} 
Effect $^{\mathrm{u}}$ & $\begin{array}{c}\text { Percent } \\
\text { marketable }\end{array}$ & SSC & TA & SSC/TA & Hedonic & Sweetness & Tartness & Freshness \\
\hline Heating (H) & NS & $* *$ & $* *$ & $* *$ & $* *$ & $* *$ & NS & $* *$ \\
Waxing (W) & NS & NS & NS & NS & $* *$ & NS & NS & $* *$ \\
Storage (S) & NS & NS & $* *$ & $* *$ & $* *$ & $* *$ & NS & $* *$ \\
$\mathrm{H}^{*} W$ & NS & NS & NS & NS & NS & NS & NS & NS \\
$\mathrm{H}^{*} \mathrm{~S}$ & NS & NS & NS & NS & NS & NS & NS & NS \\
$\mathrm{W}^{*} \mathrm{~S}$ & NS & NS & NS & NS & NS & NS & NS & NS \\
$\mathrm{H}^{*} \mathrm{~W}^{*} \mathrm{~S}$ & NS & NS & NS & NS & NS & NS & NS & NS
\end{tabular}

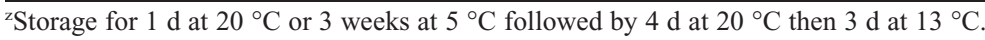

${ }^{\mathrm{y}}$ Values are means showing the main effects across all other treatment effects.

xPercentage of fruit with slight or no surface injury that would be marketable on the basis of visual quality.

${ }^{w}$ Hedonic score of likeability rating from 1 (extremely dislike) to 9 (extremely like).

vThe degree of sweetness, tartness or fresh flavor present, with the rating using a line scale from 1 to 150 , with a higher number being sweeter, fresher but less tart.

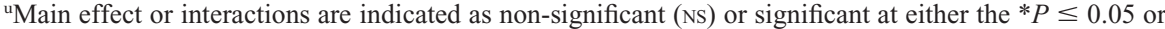
$* * P \leq 0.01$ level.

$\mathrm{SSC}=$ soluble solids concentration; $\mathrm{TA}=$ titratable acidity; HTFA $=$ high-temperature forced air.

Table 2. Influence of heat treatment and timing of waxing on navel orange sensory attributes after storage for 3 weeks at $5{ }^{\circ} \mathrm{C}$ followed by $4 \mathrm{~d}$ at $20^{\circ} \mathrm{C}$ and $3 \mathrm{~d}$ at $13{ }^{\circ} \mathrm{C}$.

\begin{tabular}{llccrr}
\hline Treatment & \multicolumn{1}{c}{ Waxing } & Hedonic $^{\mathrm{z}}$ & Richness $^{\mathrm{y}}$ & Sweetness $^{\mathrm{y}}$ & Tartness $^{\mathrm{y}}$ \\
\hline Control & None & $6.1 \mathrm{a}$ & $87.9 \mathrm{a}$ & $103.9 \mathrm{a}$ & $92.8 \mathrm{a}$ \\
Control & Before treatment & $6.3 \mathrm{a}$ & $97.4 \mathrm{a}$ & $116.4 \mathrm{a}$ & $101.6 \mathrm{a}$ \\
Control & After treatment & $6.4 \mathrm{a}$ & $92.6 \mathrm{a}$ & $110.8 \mathrm{a}$ & $98.8 \mathrm{a}$ \\
HTFA & None & $5.1 \mathrm{a}$ & $63.6 \mathrm{a}$ & $105.5 \mathrm{a}$ & $117.8 \mathrm{a}$ \\
HTFA & Before treatment & $3.7 \mathrm{~b}$ & $35.8 \mathrm{~b}$ & $94.6 \mathrm{a}$ & $113.8 \mathrm{a}$ \\
HTFA & After treatment & $4.7 \mathrm{a}$ & $59.0 \mathrm{a}$ & $103.3 \mathrm{a}$ & $110.2 \mathrm{a}$ \\
& & & & & Tartness \\
Effect & & Hedonic & Richness & Sweetness & $* *$ \\
HTFA (H) & & $* *$ & $* *$ & NS & NS \\
Waxing (W) & & NS & NS & $* *$ & NS \\
H $\times$ W & & $*$ & & $*$
\end{tabular}

${ }^{\mathrm{z}}$ Hedonic score of likeability rating from 1 (extremely dislike) to 9 (extremely like).

${ }^{y}$ The degree of richness, sweetness, or tartness present with the sensory rating being a line scale from 1 to 150 and a larger number being richer (more typical citrus flavor), sweeter but less tart.

${ }^{\mathrm{x}}$ Main effect or interactions are indicated as non-significant (NS) or significant at either the $* P \leq 0.05$ or $* * P \leq 0.01$ level.

Mean separation done separately for control and HTFA treatments. Values followed by a different letter for each sensory attribute within a treatment are statistically different $(P \leq 0.05)$.

HTFA = high-temperature forced air. 
tasting and the other to provide juice to determine SSC, TA, and volatile content. The fruit were carefully peeled and the portion for SSC, TA, and volatiles was juiced by hand using a commercial tabletop juicer (Model 932; Hamilton-Beach, Wilmington, NC) and the juice filtered through a screen sieve. Juice for volatiles measurement $(5 \mathrm{~mL})$ was placed into a $23 \mathrm{~mm} \times 75.5-\mathrm{mm}(20 \mathrm{~mL})$ glass vial sealed with a Teflon septum and the remaining juice for SSC and TA into a $15-\mathrm{mL}$ centrifuge tube. Each sample was from an individual fruit. All samples were held at $-20{ }^{\circ} \mathrm{C}$ until analysis. compensated refractometer (Model 10423; AO Scientific, Buffalo, NY) and TA by titration with $0.1 \mathrm{~N} \mathrm{NaOH}$ to a $\mathrm{pH}$ of 8.2 using a Radiometer TitraLab 80 (Lyon, France). Acidity was expressed as the percentage of citric acid.

The portion of each fruit to be tasted was cut into six small wedges and served to the panelists. In Tests 1 and 2, three wedges, each from a single fruit, from each treatment were presented on small white paper plates. In Test 3 , a single wedge from each treatment was placed into white, $30-\mathrm{mL}$ soufflé cups. All samples were assigned randomly generated sample numbers and presentation was in random order. Distilled water was used to cleanse
SSC was measured using a temperature- the palate between samples. Evaluations were conducted in individual, three-sided booths fitted with a door on one side through which the samples were presented. A total of 12 to 20 panelists was generally available for each tasting with the panelists for the most part being employees of the Kearney Agricultural Center in Parlier, CA. These panelists have extensive experience tasting citrus and can be considered as semiexpert. Up to nine samples were evaluated by each panelist during the tasting session. Each individual fruit was tasted by up to six panelists in Test 3, whereas the identity of individual fruit was not tracked in Tests 1 and 2. Hedonic scores indicating how well the sample was liked were given to each sample with a rating of 1 being "dislike extremely" and 9 being "like extremely." Also, ratings for sweetness, tartness, richness determined using separate 150 - $\mathrm{mm}$ line scales. The position on the scale indicated intensity with a greater number indicating more sweetness, richness (typical orange flavor), and freshness but less tartness.

\section{Volatiles measurement}

Juice samples were removed from the freezer, thawed, and 1-pentanol added as an internal standard to a final concentration of $490 \mu \mathrm{g} \cdot \mathrm{L}^{-1}$. The samples were then placed (Test 2), and fresh flavor (Tests 1 and 3) were

into a cooled $\left(5^{\circ} \mathrm{C}\right)$ tray in a Gerstel MPS2 autosampler (Gerstel, Baltimore, MD). Immediately before analysis the autosampler would move the vial into a holder that was heated at $40{ }^{\circ} \mathrm{C}$ where the sample temperature would be equilibrated for $10 \mathrm{~min}$. After equilibration, trapping of the volatiles was initiated by the autosampler by insertion of a $75-\mu \mathrm{m}$ carboxen/polydimethylsiloxane solid-phase microextraction fiber into the headspace of the vial. Trapping was conducted for $30 \mathrm{~min}$ at a temperature of $40{ }^{\circ} \mathrm{C}$ and an agitator speed of $250 \mathrm{rpm}$ after which the sample was desorbed for $2 \mathrm{~min}$ at $280{ }^{\circ} \mathrm{C}$ in the splitless inlet of an Agilent 7890 gas chromatograph (Agilent, Palo Alto, CA). The chromatograph was equipped with a DB-5 column $(30 \mathrm{~m} \times$ $0.25 \mathrm{~mm}$ ID; J\&W Scientific, Folsom, CA) and helium flow set to $1 \mathrm{~mL} \cdot \mathrm{min}^{-1}$. The oven was programmed to hold at $32{ }^{\circ} \mathrm{C}$ for $3 \mathrm{~min}$ and then ramp up to $200^{\circ} \mathrm{C}$ at $6^{\circ} \mathrm{C} \cdot \mathrm{min}^{-1}$. The detector used was an Agilent $5975 \mathrm{C}$ mass selective detector, operated in electron impact mode, scanning from mass 40 to 200 at $7.96 \mathrm{scans} / \mathrm{s}$. Identifications of compounds were performed by comparisons to the calculated retention indices, the authentic standards, and by use of the Wiley/NBS spectral library. Quantification was performed for compounds

Table 3. Volatile compounds identified in both control and heat-treated navel oranges. ${ }^{\mathrm{z}}$

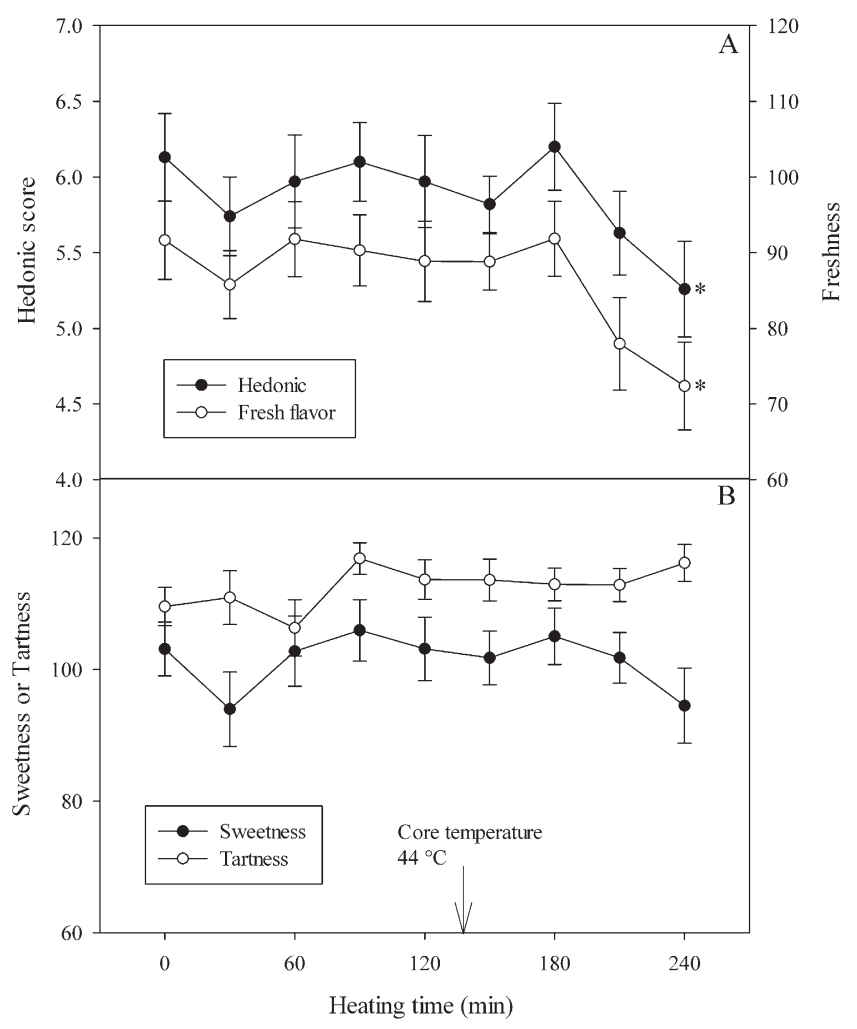

Fig. 1. Sensory panel evaluation of the hedonic score (likeability) (A) and sensory ratings of freshness (A), sweetness (B), or tartness (B) of navel oranges subjected to treatment with high-temperature forced air. The treatment consisted of heating the fruit core to $44^{\circ} \mathrm{C}$ and maintaining that temperature for $100 \mathrm{~min}$ (APHIS T103-1-a; APHIS, 2012). Fruit were removed from the treatment chamber for sensory analysis at 30 -min intervals. Fruit were evaluated after 3 weeks storage at $5{ }^{\circ} \mathrm{C}$ followed by 1 week at $20^{\circ} \mathrm{C}$. Time at which the core temperature reached $44{ }^{\circ} \mathrm{C}$ is indicated. Values significantly different $(P \leq$ 0.05 ) from the Time 0 values are marked by an asterisk. Each point represents the mean from three replicate treatment runs and bars indicate $\pm \mathrm{SE}$.

\begin{tabular}{|c|c|c|c|}
\hline Compound & $\begin{array}{c}\mathrm{RT} \\
(\mathrm{min})^{\mathrm{y}}\end{array}$ & $\begin{array}{l}\text { DB-5 } \\
\text { LRI }^{x}\end{array}$ & $\mathrm{ID}^{\mathrm{w}}$ \\
\hline Ethanol & 3.27 & 526 & $\mathrm{~S}, \mathrm{MS}$ \\
\hline Ethyl acetate & 4.88 & 617 & $\mathrm{~S}, \mathrm{MS}$ \\
\hline Pentanal & 6.58 & 700 & S, MS \\
\hline Ethyl propanoate & 7.00 & 714 & S, MS \\
\hline Methyl butanoate & 7.29 & 724 & $\mathrm{~S}, \mathrm{MS}$ \\
\hline Hexanal & 9.53 & 801 & $\mathrm{~S}, \mathrm{MS}$ \\
\hline Ethyl butanoate & 9.60 & 804 & $\mathrm{~S}, \mathrm{MS}$ \\
\hline $\begin{array}{l}\text { Ethyl 2-methyl } \\
\text { butanoate }\end{array}$ & 11.08 & 851 & $\mathrm{~S}, \mathrm{MS}$ \\
\hline (E)-2-hexenal & 11.17 & 854 & S, MS \\
\hline Styrene & 12.37 & 892 & MS \\
\hline Heptanal & 12.63 & 900 & S, MS \\
\hline$\alpha$-pinene & 13.65 & 935 & S, MS \\
\hline Sabinene & 14.82 & 975 & S, MS \\
\hline$\beta$-myrcene & 15.33 & 992 & $\mathrm{~S}, \mathrm{MS}$ \\
\hline Ethyl hexanoate & 15.53 & 999 & $\mathrm{~S}, \mathrm{MS}$ \\
\hline$\delta$-3-carene & 15.90 & 1013 & $\mathrm{~S}, \mathrm{MS}$ \\
\hline$\alpha$-terpinene & 16.13 & 1022 & S, MS \\
\hline Limonene & 16.57 & 1038 & S, MS \\
\hline (E)- $\beta$-ocimene & 16.94 & 1052 & MS \\
\hline$\gamma$-terpinene & 17.27 & 1064 & $\mathrm{~S}, \mathrm{MS}$ \\
\hline Linalool & 18.31 & 1103 & S, MS \\
\hline Nonanal & 18.41 & 1107 & $\mathrm{~S}, \mathrm{MS}$ \\
\hline Terpinen-4-ol & 20.46 & 1186 & $\mathrm{~S}, \mathrm{MS}$ \\
\hline Ethyl octanoate & 20.75 & 1197 & $\mathrm{~S}, \mathrm{MS}$ \\
\hline Decanal & 21.01 & 1208 & $\mathrm{~S}, \mathrm{MS}$ \\
\hline Carvone & 22.12 & 1254 & S, MS \\
\hline Ethyl nonanoate & 23.13 & 1296 & MS \\
\hline$\beta$-elemene & 25.57 & 1391 & MS \\
\hline Trans-caryophyllene & 26.30 & 1414 & $\mathrm{~S}, \mathrm{MS}$ \\
\hline$\alpha$-humalene & 27.04 & 1454 & MS \\
\hline
\end{tabular}

${ }^{\mathrm{z} C o m p o u n d s ~ t h a t ~ s i g n i f i c a n t l y ~ c h a n g e d ~ i n ~ a m o u n t ~}$ relative to untreated fruit as a result of heat treatment are in italics.

${ }^{\mathrm{y}}$ Retention time in minutes.

${ }^{x}$ Linear retention index (LRI) calculated using nalkanes with a DB-5 column.

${ }^{w}$ Method of identification where $\mathrm{S}=$ standards and $\mathrm{MS}=$ mass spectrometry. 
that were found to change in a statistically significant manner from the control (Time 0 ) values by using standard curves that were generated by the addition of standards into deodorized navel orange juice and adjusting for the concentration of internal standard.

\section{Statistics}

Analysis of variance (ANOVA) was conducted with the general linear model or one-way ANOVA function of SPSS (SPSS, Chicago, IL) and mean separations performed using Tukey's test when main effects or interactions were significant.

\section{Results}

In our initial evaluation of HTFA (Test 1) of navel oranges, the treatment protocol significantly altered almost all of the measured quality and sensory parameters (Table 1). Neither waxing nor storage had any influence on the HTFA effect, as indicated by the lack of significant interactions with treatment. As a result of this and the absence of any other interactions, only data from the main effects are shown in this table. SSC and TA were both reduced by HTFA, although the larger reduction in TA led to a sizeable increase in the SSC/TA ratio. The hedonic score was lowered from a value of 5.9, which is very close to "slightly like" to a value of 4.6 , which is well into the "dislike" part of the scale. The perception of both sweetness and freshness in the HTFA-treated fruit was lessened, although tartness was unaffected. Waxing acted to influence only the hedonic score and freshness, both being significantly reduced as a result of the application of wax. The amount of storage had a more widespread effect on the quality and sensory parameters with TA, hedonic score, sweetness, and freshness having lesser values in the fruit stored for 4 weeks. The losses in TA during storage also led to an increase in the SSC/TA ratio.

HTFA also influenced the evaluated sensory attributes in Test 2 , but the magnitude of the response was dependent on whether the fruit were waxed before or after treatment (Table 2). The overall effect of HTFA on the hedonic score was to reduce it from 6.3 (like slightly) to 4.5 (slightly dislike). Richness and sweetness were also both significantly less in the HTFA-treated fruit, whereas tartness was lessened. Waxing or timing of waxing had no effect in the fruit that were not subjected to HTFA. For the HTFA-treated fruit, on the other hand, both the hedonic score and the richness were significantly less in the fruit that were waxed before treatment, whereas the unwaxed fruit and those waxed just after treatment were not different from each other for these attributes. Sweetness and tartness were unaffected by waxing in both the control and HTFAtreated fruit.

In Test 3, a HTFA treatment of $240 \mathrm{~min}$ was required before the hedonic score was significantly reduced from that of the initial (Time 0) fruit (Fig. 1A). This time duration was needed to fulfill the treatment requirements. At that time point, the hedonic score had declined from an initial value of 6.1 (like slightly) to 5.3 (just above neither like nor dislike). This change was mirrored by that of the fresh flavor attribute, which was significantly lower (less fresh taste) in fruit treated for $240 \mathrm{~min}$ in comparison with the Time 0 fruit. Sweetness and tartness did not change in a statistically significant manner over the course of the experiment (Fig. 1B).

Thirty volatiles were identified in the orange juice samples (Table 3 ) with the four volatiles that changed significantly as a result of HTFA treatment being shown in Figure 2. Ethyl propanoate, methyl butanoate, ethyl hexanoate, and ethyl butanoate were for the first $150 \mathrm{~min}$ to 180 min unchanged in amount as a result of treatment but increased rapidly in concentration from that time onward.

\section{Discussion}

It is clear from this study that HTFA treatment of navel oranges by heating the core temperatures to $44^{\circ} \mathrm{C}$ and then holding at that temperature for $100 \mathrm{~min}$ [USDA APHIS Plant Protection and Quarantine Manual, T103-1-a (APHIS, 2012)] had a negative effect on the sensory quality of the fruit. This adverse effect of heat on sensory quality was also noted in our earlier study that used a heat treatment protocol that required a higher core temperature of
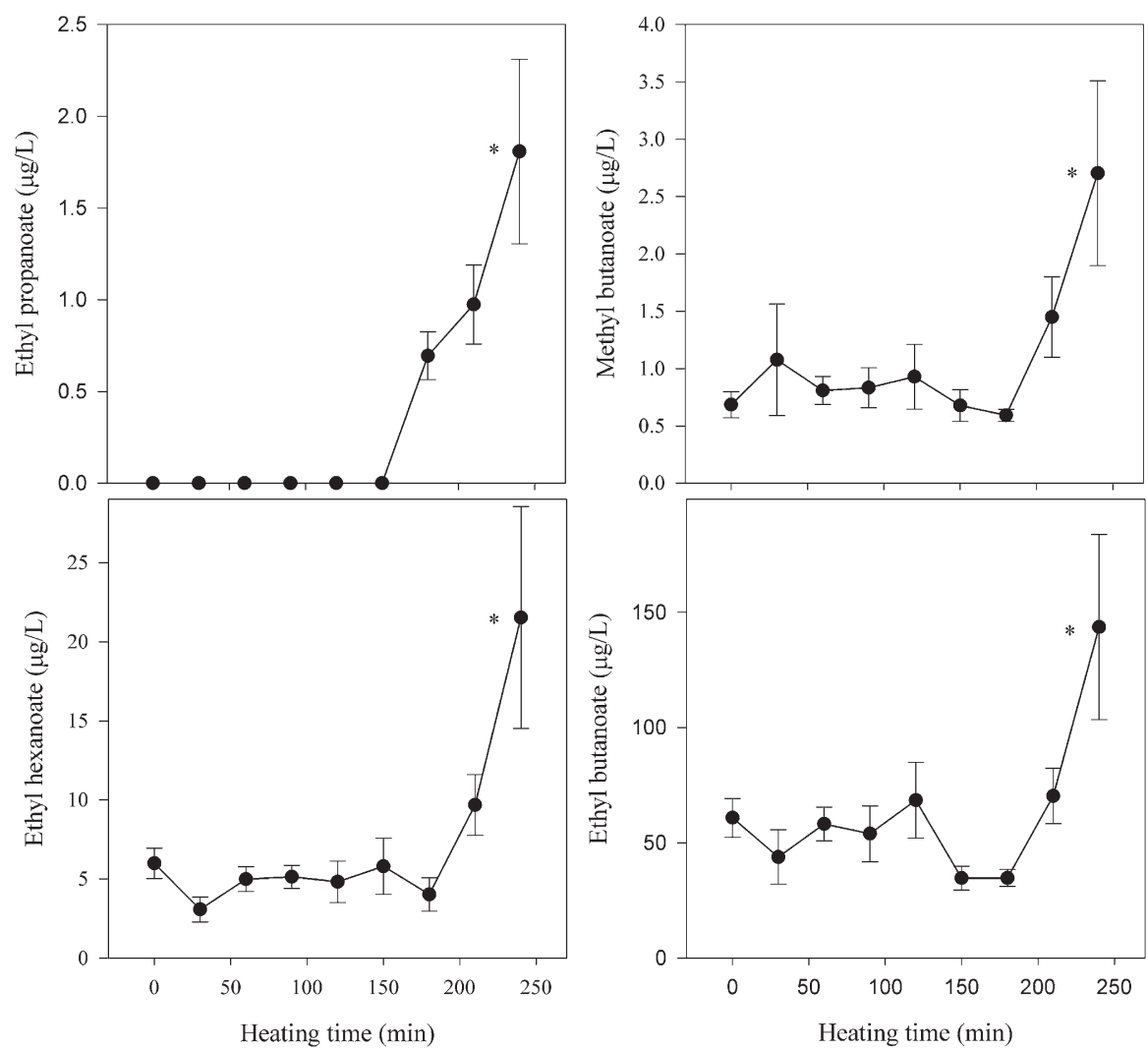

Fig. 2. Changes in flavor volatile concentration in navel oranges during treatment with high-temperature forced air. The treatment consisted of heating the fruit core to $44{ }^{\circ} \mathrm{C}$ and maintaining that temperature for $100 \mathrm{~min}$ (APHIS T103-1-a; APHIS, 2012). Fruit were removed from the chamber and sampled for volatile content at 30-min intervals during the course of the treatment. Fruit were sampled after 3 weeks storage at $5{ }^{\circ} \mathrm{C}$ followed by 1 week at $20^{\circ} \mathrm{C}$. Values significantly different $(P \leq 0.05)$ from the Time 0 values are marked by an asterisk. Each point represents the mean from three replicate treatment runs and bars indicate $\pm \mathrm{SE}$. $47.2^{\circ} \mathrm{C}$ to be applied (Obenland et al., 1999) and in a few other prior studies that have reported some negative effects of heat on citrus flavor (Shellie et al., 1993; Shellie and Mangan, 1994). In contrast, Schirra et al. (2005) applied a similar treatment as was used in this test to 'Valencia' oranges and found no effect on flavor when the fruit core temperature was taken to and maintained at $44^{\circ} \mathrm{C}$. In this study, the poorer flavor of the HTFAtreated fruit relative to untreated fruit appears to at least partly be the result of a loss in the perception of freshness (Table 1). This loss in flavor quality was also evidenced in lower flavor richness (typical navel orange flavor) scores in the HTFA-treated fruit (Table 2). Although the SSC/TA ratio was increased by HTFA treatment in this study (Table 1), it is unclear whether this had any influence on the loss of flavor quality. Generally, a higher $\mathrm{SSC} / \mathrm{TA}$ ratio is desired because the fruit are perceived to be sweeter, although too high of a ratio can cause the fruit to be bland (Obenland et al., 2009). Interestingly, treated fruit in Tests 1 and 2 were judged by sensory panelists to be less sweet, although the SSC/TA ratios were higher in the HTFA-treated fruit. It is possible that off-flavors are acting in the treated fruit to lessen the perception of sweetness. Neither sweetness nor tartness was significantly altered by HTFA in the final test (Fig. 1B). 
Waxing of the fruit before treatment greatly worsened the negative effects of HTFA on flavor, although waxing after treatment did not do so (Table 2). One potential reason for this could be that the wax acts to restrict the exit of volatile flavor compounds from the fruit that quickly form in response to the HTFA treatment and cause off-flavor.

Release of off-flavor compounds from citrus is believed to play a role in the overall internal concentration of these compounds and in determining the resulting flavor (Shi et al., 2007). Also, accelerated development of anaerobiosis in the fruit resulting from the combination of heat and restricted gas exchange could be involved. The inability to wax fruit before HTFA treatment would be a concern commercially because ideally the fruit would be sorted by size and packed before treatment to eliminate those fruit sizes and quality grades that are not destined for export and that do not require treatment. It is also during this stage of processing that wax is applied to the fruit, necessitating that changes be made to current orange fruithandling practices if HTFA was to be successfully implemented as a routine quarantine treatment.

It was of interest to estimate the duration of HTFA treatment needed for flavor alteration to occur to ascertain if it might be possible to modify the treatment time to minimize such quality loss. Loss in flavor quality did not become apparent until after core temperatures had been at $44{ }^{\circ} \mathrm{C}$ for at least $80 \mathrm{~min}$ because only at the final time point was the decline in hedonic score and fresh flavor rating significantly different from the control (Fig. 1). This indicates that orange flavor was fairly heattolerant but it is unclear if the duration or intensity of the treatment could be sufficiently reduced to eliminate flavor loss and still ensure that the treatment was efficacious as a quarantine treatment. Increased heating rate or lowered oxygen level in the treatment chamber may be potential approaches to try to achieve this. It should also be recognized, however, that the experience that our panel has with tasting citrus may make them more sensitive in detecting flavor changes than the average consumer.

A loss in fresh flavor or, conversely, an enhancement in old or off-flavor as was noted in this study suggests that changes in flavor volatiles occur as a result of HTFA treatment. This idea was supported by identification and quantification of flavor volatiles present in the fruit, which identified four esters that were considerably enhanced in amount by this treatment. Of these two, ethyl hexanoate and ethyl butanoate were both present in concentrations well exceeding published aroma thresholds for standards of these compounds in an orange juice matrix (Plotto et al., 2008) and could well be contributing to the loss in flavor quality (Fig. 2). The timing of the increase in concentration of these esters also closely matched that of the change in flavor. Although these compounds may contribute positively to flavor at the levels found in untreated fruit, at higher concentrations, they may alter the flavor balance and act to help cause the off-flavor that was found after HTFA treatment. Further work is needed to determine if one or more of these esters could be used as marker(s) to facilitate determining HTFA treatment combinations that are not injurious to flavor quality.

\section{Literature Cited}

APHIS. 2012. Plant protection and quarantine treatment manual. Section 5, Treatment schedule T103. U.S. Dept. Agr. 5-2-59.

Baldwin, E.A., M. Nisperos-Carriedo, P.E. Shaw, and J.K. Burns. 1995. Effect of coatings and prolonged storage conditions on fresh orange flavor volatiles, degrees brix, and ascorbic acid levels. J. Agr. Food Chem. 43:1321-1331.

McGuire, R.G. 1991. Market quality of grapefruit after heat quarantine treatments. HortScience 26:1393-1395.

Miller, W.R. and R.E. McDonald. 1997. Comparative responses of preharvest GA-treated grapefruit to vapor heat and hot water treatment. HortScience 32:275-277.

Nisperos-Carriedo, M.O. and P.E. Shaw. 1990. Comparison of volatile flavor components in fresh and processed orange juices. J. Agr. Food Chem. 38:1048-1052.
Obenland, D., S. Collin, B. Mackey, J. Sievert, K. Fjeld, and M.L. Arpaia. 2009. Determinants of flavor acceptability during the maturation of navel oranges. Postharvest Biol. Technol. 52: $156-163$.

Obenland, D., S. Collin, J. Sievert, K. Fjeld, J. Doctor, and M.L. Arpaia. 2008. Commercial packing and storage of navel oranges alters aroma volatiles and reduces flavor quality. Postharvest Biol. Technol. 47:159-167.

Obenland, D., P. Neipp, B. Mackey, and L. Neven. 2005. Peach and nectarine quality following treatment with high-temperature forced air combined with controlled atmosphere. HortScience 40:1425-1430.

Obenland, D.M., M.L. Arpaia, R.K. Austin, and B.E. MacKey. 1999. High-temperature forcedair treatment alters the quantity of flavorrelated volatile constituents present in navel and Valencia oranges. J. Agr. Food Chem. 47: 5184-5188.

Plotto, A., C.A. Margaría, K.L. Goodner, and E.A. Baldwin. 2008. Odour and flavour thresholds for key aroma components in an orange juice matrix: Esters and miscellaneous compounds. Flavour Fragrance J. 23:398-406.

Schirra, M. and G. D'hallewin. 1997. Storage performance of Fortune mandarins following hot water dips. Postharvest Biol. Technol. 10: 229-238.

Schirra, M., M. Mulas, A. Fadda, I. Mignani, and S. Lurie. 2005. Chemical and quality traits of 'Olinda' and 'Campbell' oranges after heat treatment at 44 or $46^{\circ} \mathrm{C}$ for fruit fly disinfestations. Lebenson. Wiss. Technol. 38:519-527.

Sharp, J.L. and R.G. McGuire. 1996. Control of Carribean fruit fly (Diptera: Tephritidae) in navel orange by forced hot air. J. Econ. Entomol. 89: 1181-1185.

Shellie, K.C., M.J. Firko, and R.L. Mangan. 1993. Phytotoxic response of Dancy tangerine to hightemperature, moist, forced-air treatment for fruit fly disinfestation. J. Amer. Soc. Hort. Sci. 118: 481-485.

Shellie, K.C. and R.L. Mangan. 1994. Postharvest quality of 'Valencia' orange after exposure to hot, moist, forced air for fruit fly disinfestation. HortScience 29:1524-1527.

Shi, J.X., E.E. Goldschmidt, R. Goren, and R. Porat. 2007. Molecular, biochemical and anatomical factors governing ethanol fermentation metabolism and accumulation of off-flavors in mandarins and grapefruit. Postharvest Biol. Technol. 46:242-251. 